\title{
Wave Energy from the North Sea: Experiences from the Lysekil Research Site
}

\author{
Mats Leijon • Cecilia Boström • Oskar Danielsson • Stefan Gustafsson • \\ Kalle Haikonen · Olivia Langhamer · Erland Strömstedt • \\ Magnus Stålberg · Jan Sundberg · Olle Svensson · Simon Tyrberg • \\ Rafael Waters
}

Received: 9 April 2008/Accepted: 23 September 2008/Published online: 10 October 2008

(C) The Author(s) 2008. This article is published with open access at Springerlink.com

\begin{abstract}
This paper provides a status update on the development of the Swedish wave energy research area located close to Lysekil on the Swedish West coast. The Lysekil project is run by the Centre for Renewable Electric Energy Conversion at Uppsala University. The project was started in 2004 and currently has permission to run until the end of 2013. During this time period 10 grid-connected wave energy converters, 30 buoys for studies on environmental impact, and a surveillance tower for monitoring the interaction between waves and converters will be installed and studied. To date the research area holds one complete wave energy converter connected to a measuring station on shore via a sea cable, a Wave Rider ${ }^{\mathrm{TM}}$ buoy for wave measurements, 25 buoys for studies on environmental impact, and a surveillance tower. The wave energy converter is based on a linear synchronous generator which is placed on the sea bed and driven by a heaving point absorber at the ocean surface. The converter is directly driven, i.e. it has no gearbox or other mechanical or hydraulic conversion system. This results in a simple and robust mechanical system, but also in a somewhat more complicated electrical system.
\end{abstract}

Keywords Wave power - Renewable energy $\cdot$ Sea trial $\cdot$ Linear generator · Point absorber $\cdot$ Environmental impact

M. Leijon · C. Boström $(\bowtie) \cdot$ K. Haikonen · E. Strömstedt · M. Stålberg · J. Sundberg ·

O. Svensson $\cdot$ S. Tyrberg $\cdot$ R. Waters

Swedish Centre for Renewable Electric Energy Conversion, Department of Engineering Sciences, Division for Electricity, The Ångström Laboratory, Uppsala University, Box 534, 75121 Uppsala, Sweden

e-mail: cecilia.bostrom@angstrom.uu.se

M. Leijon

e-mail: mats.leijon@angstrom.uu.se

O. Danielsson · S. Gustafsson

Seabased Industry AB, Dag Hammarskjölds väg 52B, 75183 Uppsala, Sweden

O. Langhamer

Department of Animal Ecology, Evolutionary Biology Centre, Uppsala University, Norbyv. 18 D, 75236 Uppsala, Sweden 


\section{Introduction}

Presently, in the light of climate change and increasing energy demand, the focus on renewable energy production is considerable. Among the renewable energy sources wave power is gaining increased attention (Callaway 2007) as ocean waves presents an untapped renewable energy source of high energy density. The global wave power potential has been estimated to be in the order of 1 TW (Falnes and Løvseth 1991). Several attempts have been made to harvest this energy through different kinds of wave energy converters (WEC:s). Examples of well-known full-scale sea trials for wave energy conversion are the AWS (Prado et al. 2005), the Pelamis (Ocean Power Delivery 2004) and the Wave Dragon (Soerensen et al. 2003). The overtopping construction TAPCHAN and OWC's, such as the Pico and the LIMPET plant, are examples of full-scale shoreline devices (WaveNet 2003).

Today several research facilities which have been established by institutes and regional and/or national initiatives with the aim of promoting wave energy research and development exist. In the UK, especially, two comprehensive efforts to promote wave and tidal energy technology are seen in the projects of the Wave Hub located West of Cornwall, and the facilities established at the European Marine Energy Centre (EMEC) on the Orkney Islands. EMEC is located off mainland Orkney, North of Scotland, UK. ${ }^{1}$ At the EMEC test site, which is intended for testing of wave and tidal energy converters, late-research and pre-commercial developers are encouraged to evaluate the performance of their devices for proof-of-concept and from the point of view of electricity production. An existing electric infrastructure for grid-connection to mainland Orkney is available. The connection point is an on-shore substation located at Billia Croo at Stromness on the South West of mainland Orkney. The substation facility offers incoming power metering circuit breakers, power factor correction and fault protection for four different test berths, sharing a total connection capacity of $7 \mathrm{MW}$ at $11 \mathrm{kV}$ (Norris and Droniou 2007). In September of 2007 the UK Government gave planning approval for the so-called Wave Hub project, an underwater socket to be located off Cornwall, UK. The Wave Hub is similar to the EMEC test site facility in that it will provide grid connection for several different developers for longterm testing and electricity production into the UK grid. The $£ 28 \mathrm{M}$ project is undertaken by The South West of England Regional Development Agency (SWRDA). The depth at the $8 \mathrm{~km}^{2}$ site, which is located $1.6 \mathrm{~km}$ offshore, is around $50 \mathrm{~m}$. The facility aims at connecting the first devices during 2009, in what is said will be the world's first large-scale wave farm ${ }^{2}$ (Marsh 2007).

The main characteristic of the interaction between waves and a WEC is that energy is converted at large forces and low velocities. Traditional wave power take-off systems use hydraulics (Henderson 2006) or turbines (Frigaard et al. 2004) to convert slow-moving wave motions to a high speed rotating motion suitable for conventional generators. This leads to relatively complex mechanical systems with a large number of moving parts. A different approach is to use a direct driven WEC with a linear generator (Mueller and Baker 2002; Polinder et al. 2005). The advantage of this set-up is a less complex mechanical system with potentially a smaller need for maintenance. One of the drawbacks is a more complicated transmission of the power to the grid, since the generated voltage will vary in both frequency and amplitude.

\footnotetext{
1 www.emec.org.uk, date: 14 Feb 2008.

${ }^{2}$ http://wavehub.co.uk, date: Feb 14, 2008.
} 
The approach of a directly driven linear generator is taken in the Swedish Lysekil project. This concept is based on a three-phase permanent magnet linear generator placed at the seabed, connected to a buoy via a stiff line. The hydrodynamic action of the ocean waves force the buoy to move in a heaving motion. The buoy then drives a translator in the generator. The translator is equipped with permanent magnets and induces current in the stator windings of the generator, thereby converting the energy of the waves into electric energy. The translator is also connected with springs to the generator foundation in order to retract the translator in the wave troughs. In the top and bottom of the generator, end stops are placed in order to limit the translator stroke length in the most powerful sea states. An overview of all different components installed at the Lysekil research site, including a detailed view of the generator, is illustrated in Fig. 1.

The choice of three-phase permanent magnet linear generators for wave energy conversion was based on a previous study (Leijon et al. 2005). Results from Finite Element Method (FEM) based computer simulations and economical considerations indicated that small wave energy converter units ranging down to $10 \mathrm{~kW}$ could have an impact on tomorrow's sustainable electricity production. The technology of the linear generator was assumed to be somewhat depth independent and the unit size of $10 \mathrm{~kW}$ for power conversion was assumed to match a significant wave height in the range of $2 \mathrm{~m}$, found in near shore and sheltered waters typical for Swedish conditions. However, the generator and the mechanical structure of the generator are designed to handle great over-loads in terms of electrical power and mechanical strains. This makes it possible to e.g. change the buoy to a buoy with larger diameter in the offshore experiments without damaging the WEC.

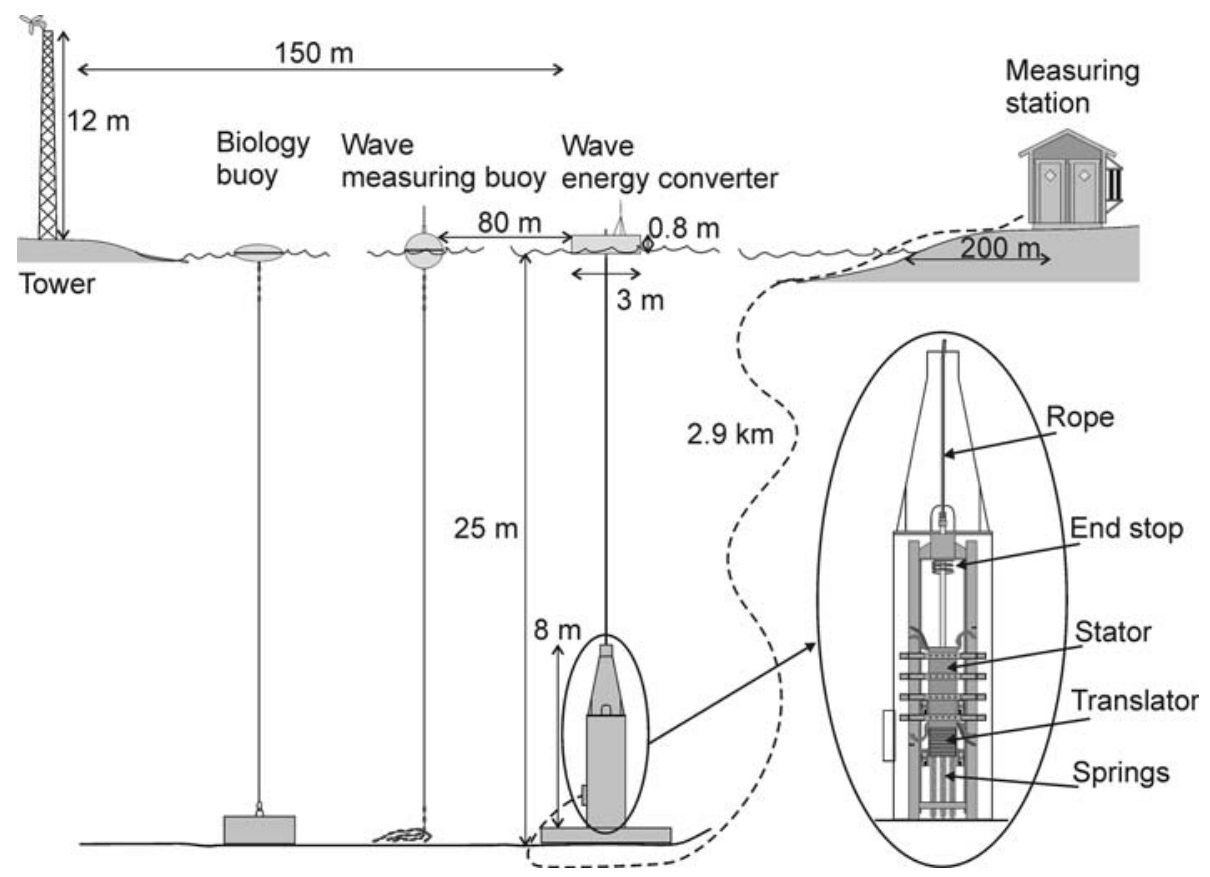

Fig. 1 Overview of the various types of components installed at the Lysekil research site 
A wave power farm consisting of a number of smaller WEC units, using linear generators, was found to have the potential of harvesting the wave energy of coastal areas (Leijon et al. 2003; Henfridsson et al. 2007). The simulations did thus indicate the possibility for electrical power production in places with comparatively calm seas. However, further simulations and experimental verifications were needed since the results were based on a simplified buoy-wave interaction model.

The Lysekil wave energy research site, located near the city of Lysekil on the Swedish West coast, was established in order to evaluate the wave energy converter concept. The project is run by the Swedish Centre for Renewable Electric Energy Conversion at Uppsala University and has several purposes. The first purpose is to test and evaluate the proposed WEC concept. The behaviour of the pilot WEC will be studied both when it works as a single unit and as part of a cluster. Secondly, the system aspects are of importance. As the induced voltages from the WEC will vary both in amplitude and frequency, the generator cannot be connected directly to the grid. Therefore, the current from each WEC will be rectified and added together with others before it is again inverted. Depending on the chosen set-up for this, other parts of the system, e.g. buoy energy absorption, will also be affected. An ongoing study focuses on how to make the system work well as a whole. Thirdly, environmental impacts and interactions are studied focusing on marine organisms, ranging from small bottom dwelling organisms living in the seabed, organisms involved in biofouling (and therefore of interesting relation to mechanical wear and maintenance) to vertebrates (including fish, seabirds and marine mammals).

This paper presents an update on the status of the Lysekil project with results from the experimental activities presented and discussed in detail. The results include descriptions of the strategies and procedures for the construction of the research site and the installation of its components, e.g. the first prototype WEC (see Fig. 1). In further detail, the paper presents the wave climate at the research area and elaborates on results that have been attained since the deployment of the WEC in 2006 and the biology buoys in 2005/2007. The WEC has been operated in real ocean seas for several months during three different time periods. Electrical power, buoy motion and mooring line forces have been measured and results are analyzed to increase the knowledge of direct driven linear generator WEC dynamics. Results demonstrate how wave energy conversion, using the concept at hand, is functioning in calm as well as rough offshore sea states. Results are also presented on how the WEC operates when it is connected to a non-linear load, which will be the case when more WEC:s are interconnected and connected to the electric grid. They will then form an array of converters, a wave farm. Sediment data has been collected and subjected to environmental studies. Results from the environmental studies show that both species abundance and biodiversity is greater in the research area than in the associated control area. It is also suggested that the area, despite the ongoing research activities, has the possibility to recover after earlier trawling in the area.

\section{The Lysekil Research Site}

The Lysekil research site is situated on the Swedish West coast, about $100 \mathrm{~km}$ North of Gothenburg, near Lysekil. The site is located $2 \mathrm{~km}$ offshore, between a northern $\left(58^{\circ} 11^{\prime} 850 \mathrm{~N} 11^{\circ} 22^{\prime} 460 \mathrm{E}\right)$ and a southern navigational marker $\left(58^{\circ} 11^{\prime} 630 \mathrm{~N}\right.$ $11^{\circ} 22^{\prime} 460 \mathrm{E}$ ) signalling the research area to avoid interference with shipping (Gustafsson et al. 2005). It covers an area of $40,000 \mathrm{~m}^{2}$ and will by 2013 contain approximately 35 
buoys: ten with generators and an additional 25 for environmental impact studies (Sundberg and Langhamer 2005). The area is exposed to westerly winds and waves.

In May 2006 SGU (Geological Survey of Sweden) made a survey of the bottom conditions in the test site area. All measurements and sampling were done from the survey ship U/S Ocean surveyor. The survey showed that the bottom in the central part of the test site consists of an even surface that has a light incline to the West. The water depth in the in the eastern part is $24 \mathrm{~m}$, and in the western part $25 \mathrm{~m}$. The bottom material in the test site area consists mainly of sandy silt. Some smaller areas are covered with rougher material. The silt/sand layer is about $1 \mathrm{~m}$ thick. Underneath the sand/silt layer there is a layer of glacial clay that is several tens of meters thick. The bottom surface in the test site area is surrounded by primary rock on most sides. The occurrence of exposed primary rock at the bottom, friction soil with transport forms, and a large content of shell fragments indicate frequent and powerful movements in the water close to the bottom in the whole test site area (Cato and Kjellin 2008).

The limited water depth at the site allows for divers to perform regular inspections of devices placed at the seabed and to perform marine environmental studies. In addition, the area is situated only eight $\mathrm{km}$ from Kristineberg Marine Research Station ${ }^{3}$ and Klubban Biological station (Uppsala University), where well-equipped research facilities and larger vessels are available. Also, smaller vessels are available for more regular visits and work in the project area.

No full scale Environmental Impact Assessment was needed due to the small scale (area) of the project and its non-commercial research directed function. However, consultations with the County Administration and parties involved, e.g. fishing organizations, local governments and the National Maritime Administration were necessary in order to obtain a number of permits and thereby the use of the area. In 2004-2005 the County Administration gave a number of necessary permission for ten wave energy converters, along with an additional 30 buoys for environmental impact studies. A special permit was needed for the sea cable from the project area to the mainland grid at the nearby island of Gullholmen, see the dash-dotted line in Fig. 2. All permits presently run until the end of 2013. After this, the equipment has to be removed (decommissioned) unless a prolongation is applied for and approved.

\section{Initial Studies}

A Datawell Waverider buoy has provided time series of wave elevations at the Lysekil research site continuously since April 2004. The measured spectrum has been used for numerical studies of the power capture capability of a cylindrical buoy using potential theory (Eriksson et al. 2005). It has also been used to calculate the wave climate of the site (see Fig. 7 in the results section).

In March 2005, the first experimental setup at the Lysekil research site was launched. The purpose of the experiment was to measure the maximum line force from a buoy with a diameter of $3 \mathrm{~m}$ and a height of $0.8 \mathrm{~m}$, simulating a wave generator that is disconnected from the grid and hence is operating without any damping in the system. The results were used as input data for the design of the first wave generator unit and to verify the calculations of the dynamics of non-damped systems (Eriksson et al. 2006). In the experiment,

\footnotetext{
3 www.kmf.gu.se.
} 


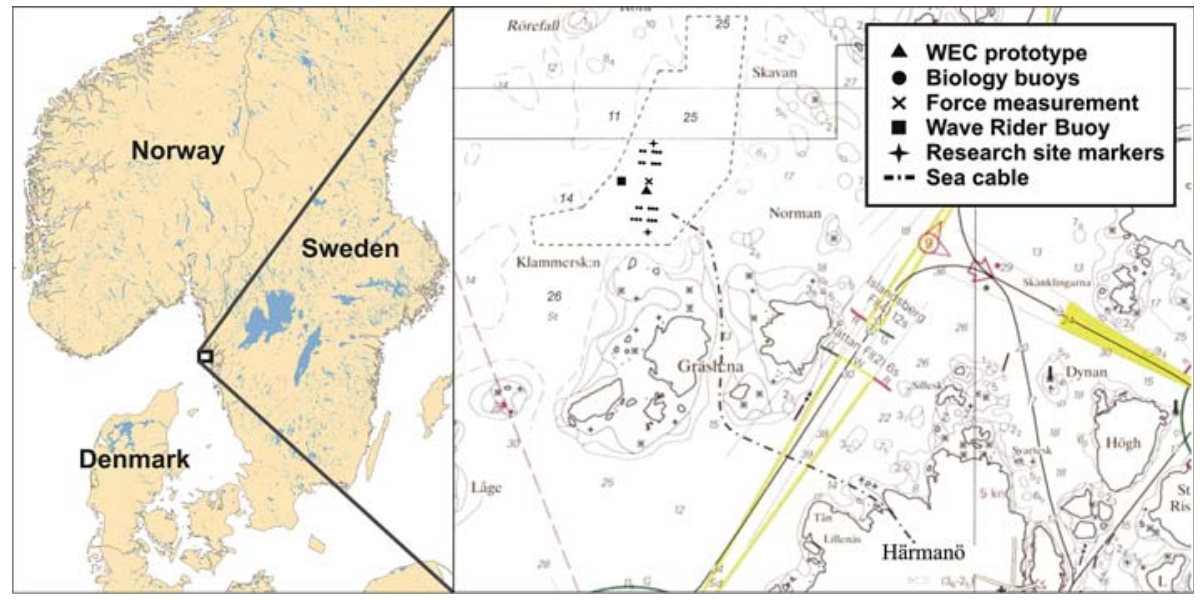

Fig. 2 Sea chart showing the area suitable for a power plant test site in dashed lines. The chosen test site is situated in the southernmost part of the area. (C) Sjöfartsverket, permit no. 08-01465

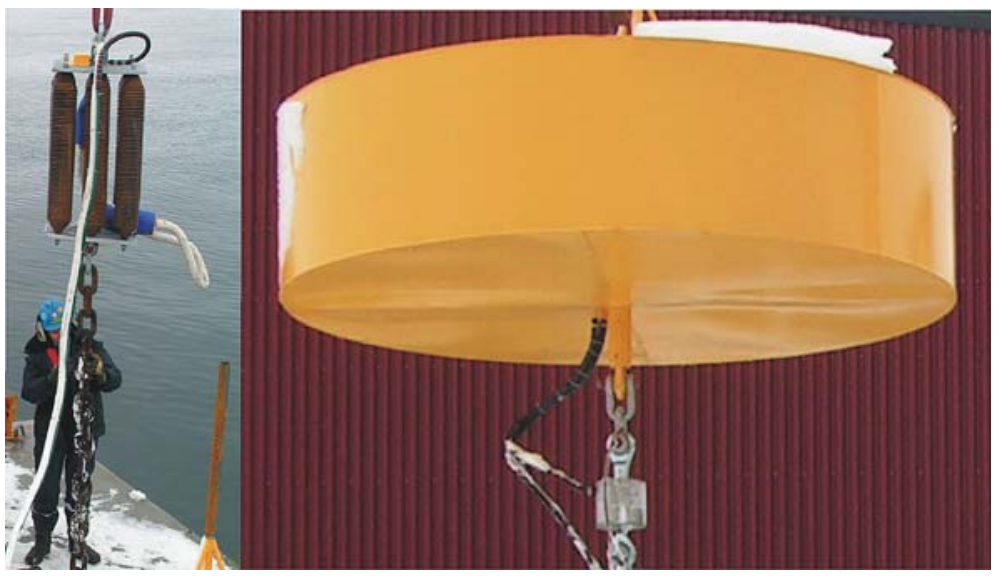

Fig. 3 The packet of springs to the left, the force transducer below the buoy to the right

a force transducer was connected between a packet of springs and the buoy, see Fig. 3 . The springs pull the buoy downwards in wave troughs. A line was connected in parallel with the springs to prevent the springs from being extended too far. In the set-up, the line also limited the stroke length of the springs, thus having the same effect as an end stop. The spring constant was chosen so that half of the buoy was under water when the springs were stretched to half its maximum length. The force transducer was sampled with $16 \mathrm{~Hz}$ and the data was transmitted wirelessly through the GSM network (Fig. 8 in the results section show results of force measurements carried out long after this initial study, at a stage when the buoy was connected to a real generator).

A preparatory study for connecting clusters of direct driven linear generators to the grid was performed (Thorburn et al. 2004) in order to prepare for future grid connection. 


\section{Installation}

\subsection{Strategy}

The establishment of the research test site has been done in several steps. The launch of the first wave power generator, including the sea cable to shore, was made in the beginning of March 2006. With different contractors working with the cable and the generator the decision was made to launch the cable first, leaving the loose end marked with a buoy. Later, on a calm day, the power plant could be launched with about $100 \mathrm{~m}$ cable attached. To prevent the generator from inducing voltage while joining the cables the buoy was fastened with the translator in its lowest position. Next, the cable ends could be raised onboard a vessel and joined together (Fig. 4). The remaining task was to let the buoy loose, which was performed by a diver.

\subsection{Cable}

The power from the WEC is transmitted to shore by a $1 \mathrm{kV}$ sea cable with $4 \times 95 \mathrm{~mm}^{2}$ copper conductors. The cable is armoured with $4 \mathrm{~mm}$ galvanized steel wire and weighs $6.2 \mathrm{~kg} / \mathrm{m}$. The cable resistance is approximately $0.5 \mathrm{Ohms}$ per phase. Due to the relatively large conductor area, the cable will, at a line-to-line voltage of $1 \mathrm{kV}$, be able to transmit the power from up to ten future WEC:s with relatively small transmission losses. The power from the first prototype WEC is transmitted directly to shore, i.e. at variable voltage and frequency according to the rating and operation of the linear generator (see the voltage curve in Fig. 8 of the results section). The distance from shore to the test site is approximately $2 \mathrm{~km}$. The largest depth along the cable path is $40 \mathrm{~m}$.

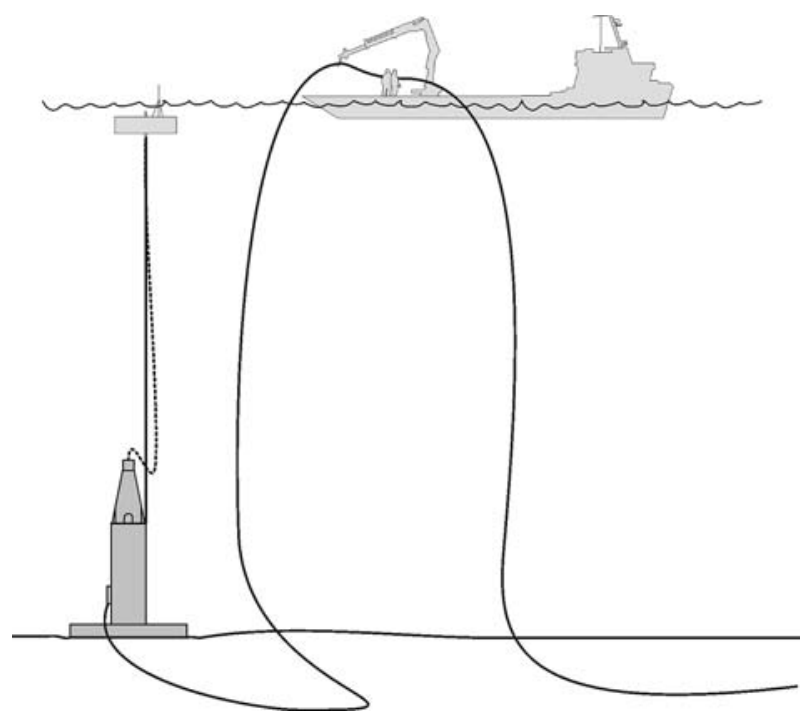

Fig. 4 The figure shows the generator placed at the sea bed. The buoy was fastened with the translator of the generator in the lowest position. The cable ends were raised onboard a vessel and joined together 


\subsection{Measuring Station}

To house the measurement equipment a measuring station has been built at Härmanö, Fig. 2. The power cable is connected to this station. The power produced in the generator during the first test period was converted to heat over a three phase delta-connected resistive load. The first measurements were made with an oscilloscope. The control, load and measurement system have then been successively expanded. There is now a remotely operated measurement and control system based on a programmable automation controller. During the second test period, the generator was connected to a non-linear load including a diode rectifier, capacitors and resistors. This system was installed in the measuring station during the autumn 2006 and spring 2007.

\subsection{Wave Energy Converter}

\subsubsection{Deployment}

For the purpose of deployment of the fully assembled WEC, a steel structure was fitted in the aft deck of a barge of $50 \mathrm{~m} \times 12 \mathrm{~m}$, see Fig. 5. The structure was built to support four pairs of $0.5 \mathrm{~m}$ long hydraulic wire jacks, two for each corner of the WEC foundation. After towing the WEC, which was hanging at the stern of the barge, from the harbour of Lysekil, the WEC was submerged at the test site, see Fig. 6. The casing of the linear generator was dimensioned for equal interior and exterior pressure. To maintain this, the casing was pressurized with nitrogen gas to 2.5 bar during the submersion. After submersion, the hose was disconnected from the casing by divers. Lifting wires were left on the sea floor and picked up after a few days.

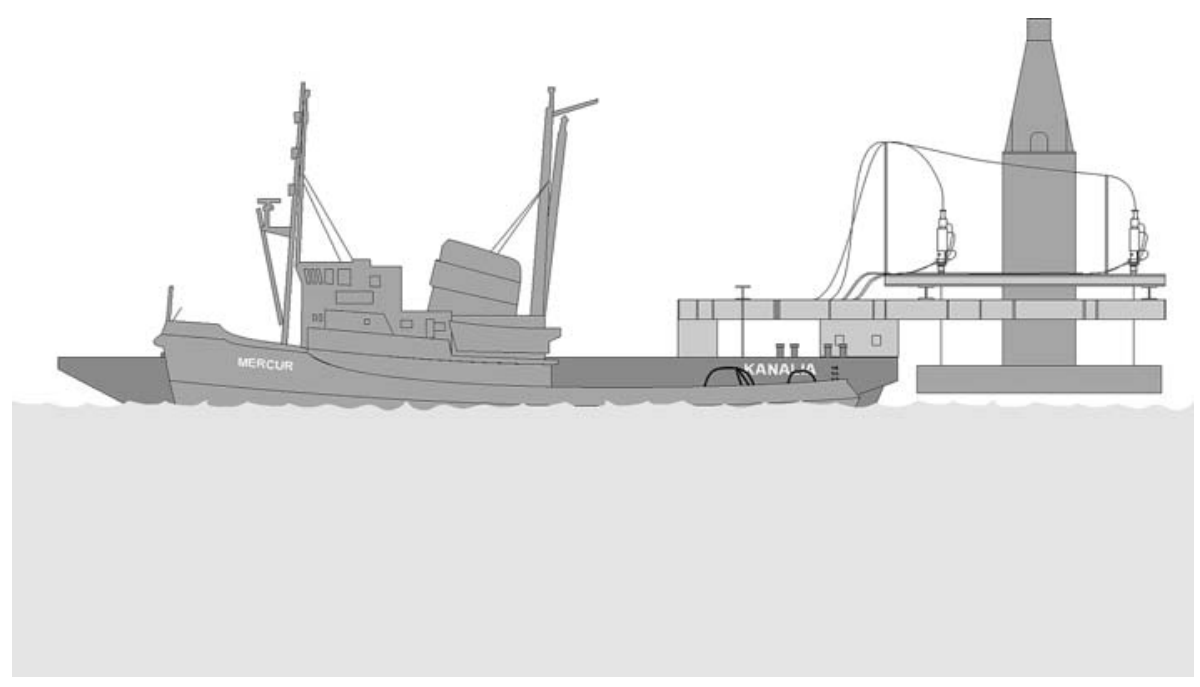

Fig. 5 Overview of the vessels equipped for the transport and launch of the WEC. A steel structure supporting four pairs of hydraulic wire jacks is fitted to a barge with the WEC hanging from the jacks. The barge is towed to the launch position by a tugboat 
Fig. 6 The WEC and buoy prepared for launch hanging in the wire jacks in the stern of the barge

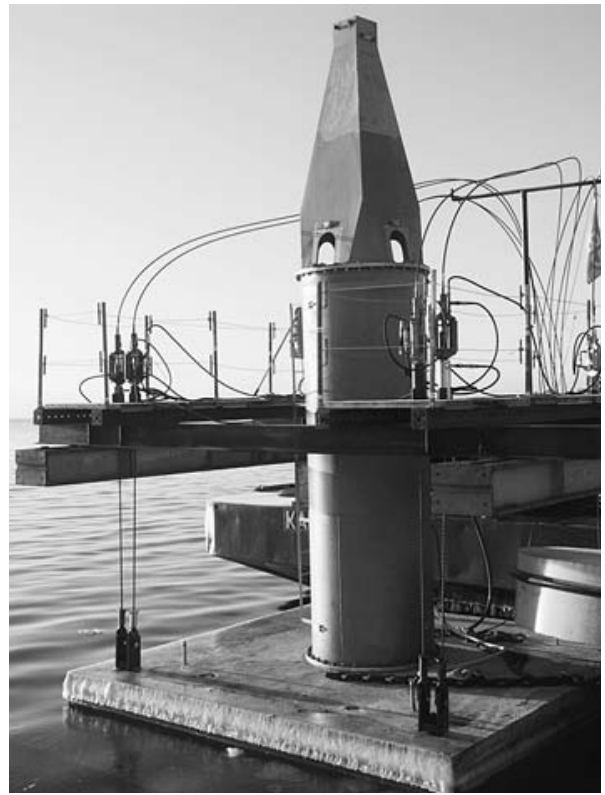

\subsubsection{Rating and Geometry Data of WEC}

The WEC is based on a direct-driven, linear, synchronous three-phase generator with a point absorber on the sea surface. The buoy, weighing approximately 1 tonne, is a flat cylinder with a diameter of $3 \mathrm{~m}$, height of $0.8 \mathrm{~m}$ and the draft at normal water level is $0.4 \mathrm{~m}$. The buoy is connected to the moving part of the generator, the translator, via a $3 \mathrm{~m}$ high rope guidance system and a hydraulic piston and piston sealing. Sea water is prevented from entering the $5 \mathrm{~m}$ long casing by a sealing enclosing the linear generator.

A translator moves in a reciprocal motion in accordance with the heaving motion of the buoy absorbing energy from the waves. The translator holds permanent magnets, which magnetize the generator, and the hard magnetic material alloy used for the magnets are $\mathrm{N} 40 \mathrm{Nd}-\mathrm{Fe}-\mathrm{B}$, having a remanent induction of $1.3 \mathrm{~T}$ and an energy product of $320 \mathrm{~kJ} / \mathrm{m}^{3}$. Magnets are mounted in horizontal rows of four magnets in each row on the four-sided translator. The number of slots per pole and phase is $6 / 5$ and each slot holds six conductors. The $16 \mathrm{~mm}^{2} \mathrm{Cu}$-conductors have circular cross section and are insulated with PVC.

Rated power of the generator is $10 \mathrm{~kW}$ at a line-to-line voltage of $200 \mathrm{~V}$ and a translator speed of $0.67 \mathrm{~m} / \mathrm{s}$, and hence the nominal current is $29 \mathrm{~A}$. The translator, which is $1,850 \mathrm{~mm}$ long, is slightly longer than the stator, which is $1,250 \mathrm{~mm}$. Total stroke length of the generator is $2,190 \mathrm{~mm}$, of which $1,800 \mathrm{~mm}$ is the free stroke length, i.e. the distance the translator is able to move without any of the end stop springs being compressed. Eight springs are connected between the generator translator and the bottom of the casing. These springs act as retracting force, thus pulling the translator and buoy downward after each wave crest. Hence, wave energy is converted to electricity in both directions of the translator motion. In Eriksson et al. (2005), a more mathematical description of the system was presented, relating the gravitational, hydrodynamic, spring and electrical forces from

${ }^{4}$ [http://www.suramagnets.se/pdf/suramagnets_sintered_nd-fe-b.pdf, date: February 26, 2008]. 
the generator to the motion of the buoy and translator. Some early results from the offshore operation in 2006 are given in (Waters et al. 2007; Stålberg et al. 2008).

\subsubsection{Observation Tower}

During the spring and summer of 2007, a lattice tower was erected on a small nearby islet (see the illustration in Fig. 1). The purpose of the tower was to serve as a base for measuring equipment related to the project. The tower is $12 \mathrm{~m}$ high and is located approximately $150 \mathrm{~m}$ from the southern edge of the buoy field.

The tower was equipped with a Sony SNC-RX550 controllable network camera during 2008, and later on, a Vaisala WXT 510 weather station and a Brüel \& Kjaer 8105 hydrophone will be installed. The purpose of this equipment is to monitor the motions of the point absorbers, measure temperature, precipitation and barometric pressure, and detect underwater noise from the generator.

To provide power for these measurements, the tower has been equipped with two $85 \mathrm{~W}$ CT85 solar cell panels, connected to a battery bank. Communication of data to shore is carried out via a $3 \mathrm{G}$ modem for wireless transmissions.

\section{Environmental Studies}

Sediment samples were taken in 2004 prior to launching of the WEC in order to investigate in the marine infauna inside the test area and in control areas. Infauna is defined as all marine organisms that live in the soft bottom sediments. Analysing species composition gives information about the biodiversity, i.e. variation in life forms within the given area. It is often used to measure the health of biological systems. This was primarily done as a part of the Environmental Statement, and in order to receive permits, but the collected data may also function as pre-project control sampling for long term impact studies. The sampling method is based on a hap-score with a diameter of $14 \mathrm{~cm}$ and sieving with a $1 \mathrm{~mm}$ sieve. This excludes all organisms smaller than $1 \mathrm{~mm}$ in size. All living animals were removed and preserved in formalin. Organisms were identified down to family or species level if possible.

Biomass data was transformed into presence-absence data analysed ANOSIM in Primer v.5 (Clark and Gorley 2006) for multivariate analyses. Diversity data (total number of individuals, total number of species and Shannon Wiener diversity (Krebs 1989)) were calculated in DIVERS (Primer v.5) and compared with a one-way ANOVA in Statistica 7.1. Shannon Wiener index measures biodiversity by describing the distribution of species, taking species richness and evenness of species into account. The index increases either by having additional unique species, or by having greater species evenness.

The first experimental setup for the marine ecological studies of wave power consisted of 4 so-called biology buoys (see illustration in Fig. 1). The buoys were cylindrical with a diameter of $1.8 \mathrm{~m}$ and a height of $0.8 \mathrm{~m}$. They were moored with stiff lines to 10-tonne concrete foundations having a diameter of $2.8 \mathrm{~m}$. There was one additional bigger buoy, with a diameter of $3 \mathrm{~m}$, moored to a 40-tonne concrete foundation.

The dimensions of the foundations were designed to handle the lifting capacity of the buoys in extreme wave conditions. The first set of biology buoys were put in place during the spring of 2005 with a distance between $100 \mathrm{~m}$ and $300 \mathrm{~m}$ from each other, all at $25 \mathrm{~m}$ depth on a seabed consisting of firm shell gravel and silt. 
In the spring of 2007, the experimental setup for marine biological studies was increased in size and complexity. An additional 21 biology buoys were installed during March and May of 2007. The new biology buoys were $2.0 \mathrm{~m}$ in diameter and $0.8 \mathrm{~m}$ in height and were moored with a steel wire to a 10-tonne concrete foundation with the same dimensions as the initial ones. The buoys were divided in two areas in the test site, a northern area and a southern area lying approximately $200 \mathrm{~m}$ apart. Within each group the biology buoys were placed out with a distance of 15-20 m between each other (see Fig. 2).Ten of the foundations were designed without various holes and eleven of them were designed with holes.

The concrete foundations for the larger buoy (weighing ca 40 tonnes) and the smaller foundations used for biology buoys (approximately 10 tonnes), can both work as artificial reefs. The differences in the foundations with and without holes were made for the environmental studies, to investigate if colonization will differ between foundations with or without holes. For many marine mobile species recruitment and survivorship are strongly related to shelter availability (Risk 1972; Luckhurst and Luckhurst 1978; Chabanet et al. 1997). Holes could have a positive effect on colonizing species.

The launch of the biology buoys was made by the ship Scandica (Swedish National Maritime Administration). At the test site the GPS of Scandica was used to find the right positions for the biology buoys. At the launch, first the buoy was put in the water and then the foundation was slowly submerged down to the seabed using the crane of the ship.

Solid structures placed in seawater most often become attractive to marine organisms in terms of "artificial reefs" lying on the seabed. Furthermore they can work as fish aggregation devices floating on the surface.

The succession of colonization patterns in different organisms has been investigated. Artificial reefs may have much to offer in terms of management, nature conservation, fishery management/enhancement and coastal defense (Jensen 2002). One important research topic is an effective, purposeful reef-design that could be applied on wave power devices as a positive side-effect to production of electricity.

\section{Results}

\subsection{Wave Climate and Wave Energy Content}

Before building the WEC, the acquired data from the wave measuring buoy was studied to determine e.g. a suitable stroke length. Recently a more thorough analysis of the wave climate at the test site has been made. In Fig. 7, 15,650 data points from 2007 have been plotted. The data is from all months except for August, and each point represents a half hour average. For every half hour, the corresponding values for energy period $T_{\mathrm{E}}$ and significant wave height $H_{\mathrm{S}}$ have been calculated. The left plot in Fig. 7 lists the occurrence of different sea states in 2007, whereas the figure to the right describes what sea states carry the greatest amount of energy over a year. The average energy flux during 2007, excluding August, was $3.4 \mathrm{~kW} / \mathrm{m}$.

While the most frequent sea state has a value for $T_{\mathrm{E}}$ around $4 \mathrm{sec}$ and $H_{\mathrm{S}}$ less than $0.5 \mathrm{~m}$, the main energy contribution comes from the more energetic sea states. Due to its relatively low energy flux, the wave climate at the Lysekil test site would not be ideal for commercial wave power production. That was, however, not the motive for choosing the site; it was chosen due to its proximity to the marine research stations described above under Test site. 

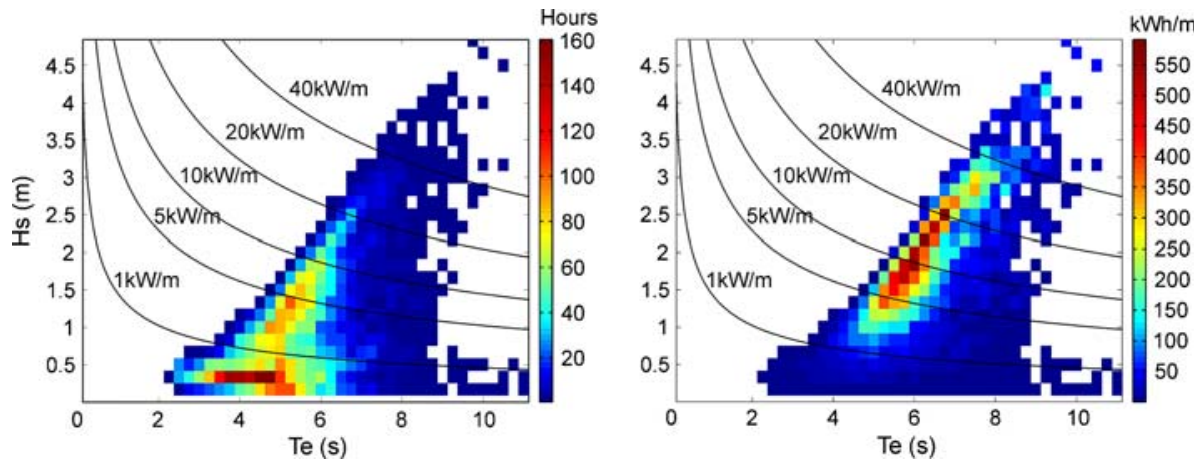

Fig. 7 The occurrence of sea states [hours] (left picture), and cumulated energy [kWh/m] (right picture) as a function of significant wave height and energy period at the Lysekil research site. The data covers all of 2007, excluding August

\subsection{WEC Output and Forces}

The generated output from the WEC has been continuously recorded in the measuring station. A time window of voltage and power is given in Fig. 8. The significant wave height during the half hour from which Fig. 8 is taken was $2.3 \mathrm{~m}$, and the load applied at the measuring station was $2.2 \mathrm{Ohm}$. A force transducer was connected between the generator and the buoy in the same way as can be seen in Fig. 3. The force from the weight of the translator added to the force from the springs in mid position is around $20 \mathrm{kN}$. Accelerometers were placed inside the buoy and have been used to calculate the vertical buoy speed. Figure 8 shows the measured buoy line force, the vertical speed of the buoy, the load voltage and power in the load during a time period of $24 \mathrm{~s}$. A detailed description of the events illustrated in Fig. 8 is given below.

The force in the buoy line of the WEC has been measured and compared with electrical power and output voltage during a set of waves. The measured time sequence is shown in Fig. 8. At first, the buoy line force is around $40 \mathrm{kN}$. At $t=0.5 \mathrm{~s}$, the translator is near its top position, which is shown by the peak in the force curve that indicates that the translator is in contact with the upper end stop. The buoy starts to move from the crest to the trough. From this point onward, the line force is reduced. The buoy and translator is accelerated downward by the springs and the translator mass and voltage is induced in the generator. This downward motion takes approximately $2 \mathrm{~s}$. At approximately $t=2 \mathrm{~s}$ to $t=3 \mathrm{~s}$, the downward motion of the buoy is larger than the downward motion of the generator translator. This results in that the line slackens and the resulting line force is almost zero. Maximum power is reached during minimum and maximum line force, assumed within generator stroke length. If the line is slack when the translator reaches the bottom, the generator stroke length is shorter than the wave height. At $t=4 \mathrm{~s}$, the translator changes its direction, which is shown by that the buoy speed becomes positive and by the change in phase order in the voltage curve. The buoy is now lifted by the hydrodynamic forces acting on its bottom surface, i.e. it is lifted by the wave until the translator reaches the upper end stop a second time. This is visible as a peak in the force curve at $t=8 \mathrm{~s}$. Some of the kinetic energy of the translator and buoy has now been converted to potential energy, which is stored in the end stop spring. The translator is now at stand still and energy is not produced until the wave height is lower than the top position of the buoy. At $t=9 \mathrm{~s}$, the 

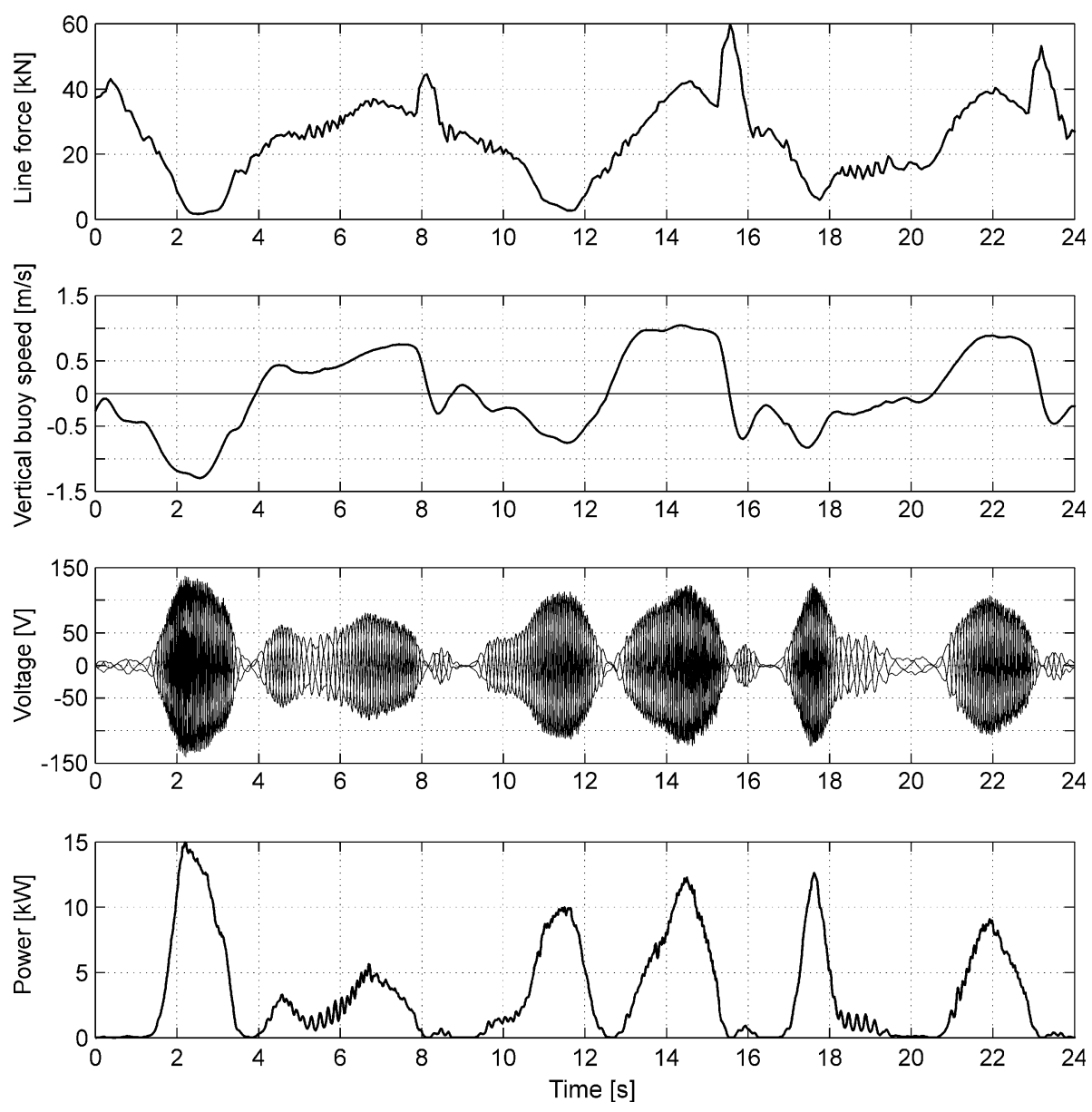

Fig. 8 Time window of measured force, speed, voltage, and power from the wave energy converter. The force measurements measure the forces on the buoy. The voltage and power is produced by the generator over a $2.2 \mathrm{ohm}$ load

translator is descending again. The line force is then about $25 \mathrm{kN}$, decreasing towards $20 \mathrm{kN}$ and below.

A higher level of damping (power extraction) results in bigger difference between the vertical motion of the wave and the speed of the translator. This will in turn result in a higher line force when the wave lifts the buoy and a lower line force when the buoy descends. This effect is clearly visible at e.g. $t=11 \mathrm{~s}$ when the translator and buoy moves downwards. If the damping is very large the line might slacken when the buoy moves downwards which then results in a line force close to zero.

At $t=12.5 \mathrm{~s}$, the translator again changes direction and starts moving upwards (see the speed curve). This time, the translator turns almost instantaneously without any time at standstill. This is most obvious looking at the voltage curve. At $t=15.5 \mathrm{~s}$, the translator again changes direction after hitting the upper end stop. The end stop spring is most likely compressed to a maximum and the line force peaks, reaching a maximum of $60 \mathrm{kN}$. The end stop spring then recoils the translator some $0.2 \mathrm{~m}$, which is visible as a 
Fig. 9 The absorbed average power per half hour $[\mathrm{kW}]$ at different sea states $[\mathrm{kW} / \mathrm{m}]$. The WEC is connected to a $4.9 \mathrm{Ohm}$ load

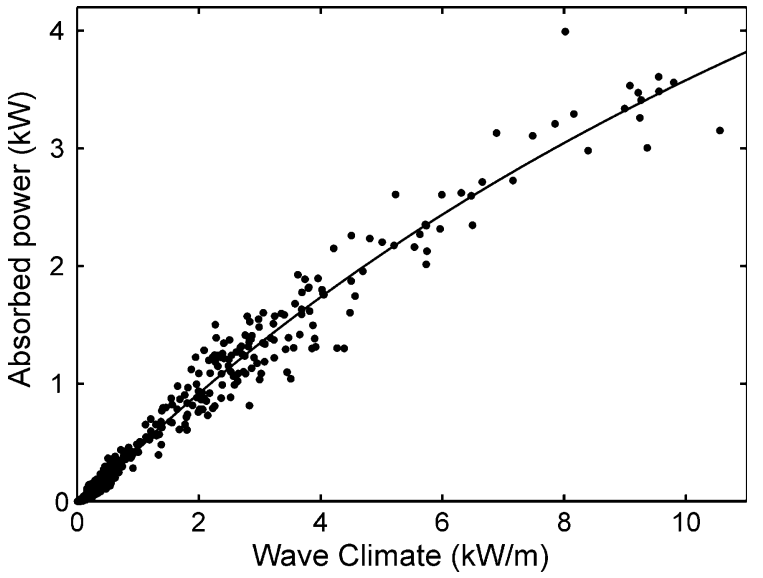

small voltage pulse in the voltage curve. The translator decelerates for a little less than a second before it continues to descend. The analyzed wave sequence ends with a smooth voltage pulse as the buoy is lifted by a wave crest at $t=21 \mathrm{~s}$. The translator moves its full stroke length until it hits the upper end stop, again resulting in a force peak of some $55 \mathrm{kN}$ at $t=23.5 \mathrm{~s}$.

The performance of the WEC can be seen in Fig. 9. The figure shows the power absorbed by the buoy (excluding generator iron losses and mechanical losses) when the WEC is connected to a resistive load of $4.9 \mathrm{ohm}$ per phase. Each data point is the average of one half hour of measurements. As can be seen, the data points in the region of $4-10 \mathrm{~kW} / \mathrm{m}$ are sparser than in the region below $4 \mathrm{~kW} / \mathrm{m}$. This is due to the low occurrence of more energetic sea states during the test period. The spread in absorbed power is also larger in the region of more energetic sea states than in the calm seas. A study on the variation in power absorption at different resistive loads was made in (Waters et al. 2007).

\subsection{Electrical System}

As previously mentioned, a conversion of the generator power output is needed before grid connection. The first step in this conversion is to rectify the voltage from each generator to a DC voltage, interconnect them in parallel, and filter the DC voltage. In order to study how this system will be designed in the future, the existing system in the measuring station was complemented with a six pulse diode rectifier and a capacitive filter. A more detailed description of the system is given in Boström et al. (2008). The total capacitance value of the ultra capacitors in the filter is $12.2 \mathrm{~F}$. The high capacitive value enables energy storage that is needed for a system including only one generator. A resistive load is connected in parallel with the capacitors and by changing the resistive value, different load characteristics were achieved in the operation of the generator. The purpose with the experiment was to study how the generator operates when it is connected to a non-linear load. The level of power smoothing can then be analyzed.

Figure 10 shows one of the three phase voltages, measured before the rectifier, and the DC-voltage, measured after the filter. The result shows that the filter can smooth out the voltage from the linear generator to a stable DC voltage. During shorter time periods as in Fig. 10, the power after the filter will also be constant. If the system is studied during 


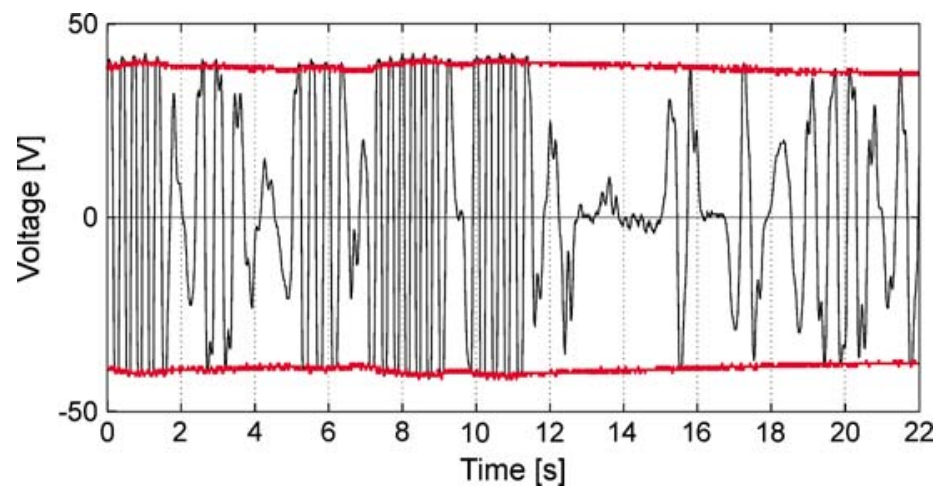

Fig. 10 DC load voltage (red) and one of the generator phase voltages on the AC-side of the rectifier (black)

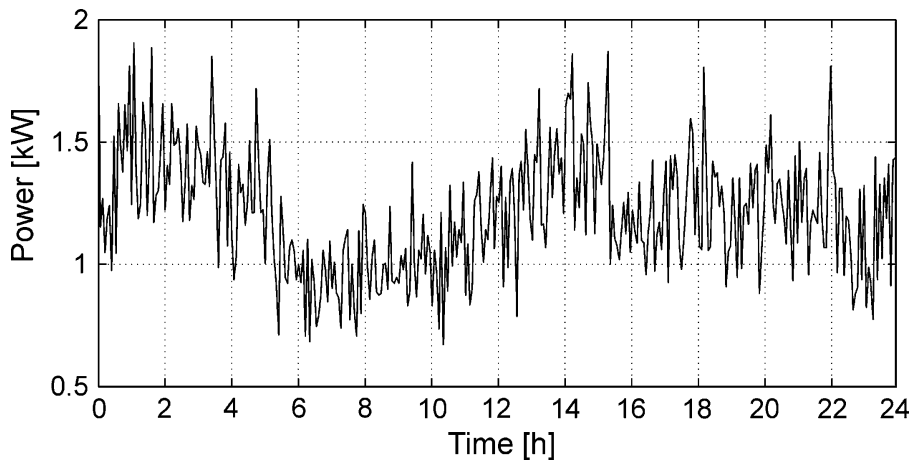

Fig. 11 Electrical power dissipated in the load on the DC-side of the rectifier in the measuring station of Island Härmanö

longer time periods (hour-scales) there will be a variation in the produced power, see Fig. 11. The variations occur due to changes in the sea state. To overcome sea state variations with capacitors, unreasonably large energy storage devices would have to be used.

\subsection{Environmental Impact}

The sediment samples from 2004 contained in total 309 individuals of 68 different species. The results of infauna sampling showed that there is a significantly higher species abundance in the buoy area compared to the control area (ANOSIM Global $R=0.259$; $p=0.004$ ) (Fig. 11). Monitoring studies at the research site before constructions showed polychaete worms were the most abundant species in the sediment (Fig. 12).

Comparing total species (S), species richness (d) and Shannon Wiener biodiversity, it all was significantly higher in the buoy area compared to the control area (Fig. 13, Table 1). Anyway, we only found very small, juvenile organisms, there were no red listed species found in those areas and there is no concern about extinction of sensitive local species. 


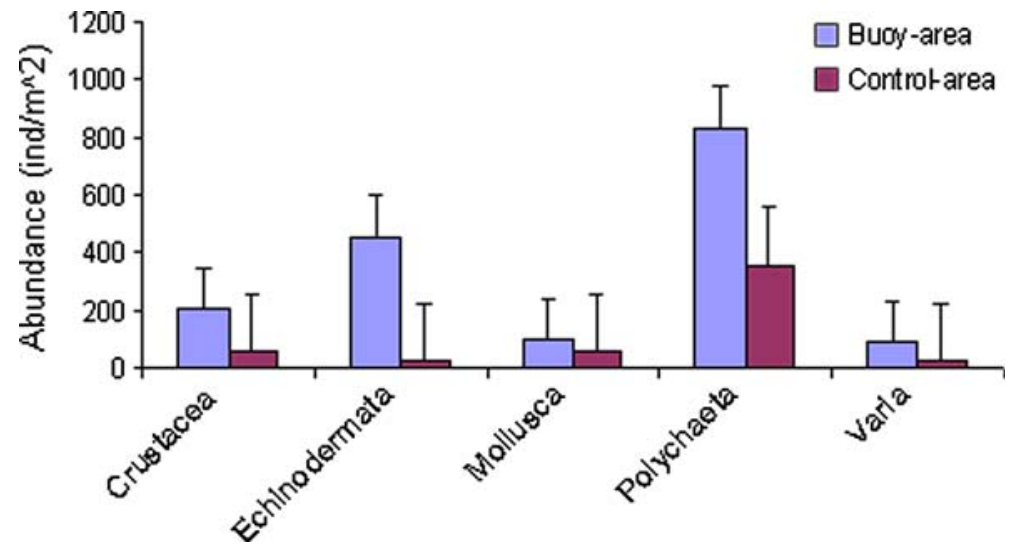

Fig. 12 Mean wet weight $(\mathrm{g})$ per $\mathrm{m}^{2}$ of macro-infauna organisms sampled in the sediment of the buoy and control area during autumn 2004. Error bars indicate standard error (95\% CI)

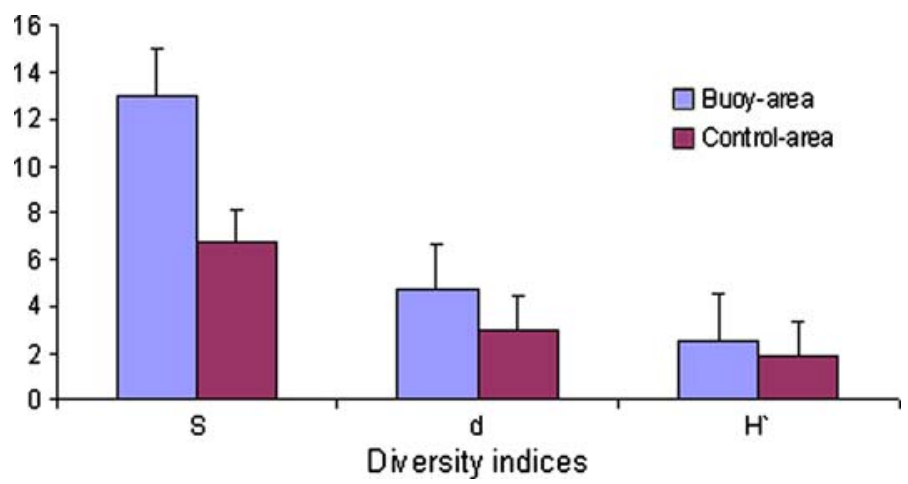

Fig. 13 Total species (S), species richness (d) and Shannon Wiener biodiversity ( $\mathrm{H}^{\prime} \log$ e) indices and for samples of macro-infauna in buoy vs. control area during autumn 2004. Error bars indicate standard error $(95 \% \mathrm{CI})$

Table 1 Sums of squares, degrees of freedom, $F$ - and $p$-value of a one-way ANOVA testing total species (S), species (S), species richness (d) and Shannon Wiener biodiversity ( $\left.\mathrm{H}^{`} \log \mathrm{e}\right)$

\begin{tabular}{lcccr}
\hline & SS & df & $F$ & $p$ \\
\hline S & 180.5 & 1 & 14.59 & 0.002 \\
d & 12.65 & 1 & 15.80 & 0.001 \\
H'log e & 1.97 & 1 & 18.90 & 0.001 \\
\hline
\end{tabular}

\section{Discussion and Conclusion}

The test site of Uppsala University, the Lysekil research site, is where the WEC prototype was deployed and offshore experiments were undertaken. The test site is presently being expanded. Two new WEC prototypes are due for deployment in 2008 together with a 
marine substation. The substation will interconnect all three wave energy converters at the test site. The new WEC:s will be electrically identical to the first prototype, installed in March of 2006. The future wave energy converter array at the Lysekil research site will be used for further research within the Uppsala University wave power project and will as such also demonstrate the functionality of the technology in a broader sense. In a few years, the array will be connected to the grid on Island Härmanö, at the location of the measuring station (see Fig. 2). Some of the preparations for this have been presented and the results are discussed below.

Figure 7 shows that the most common sea states have a relatively small significant wave height and energy period, e.g. the median significant wave height is $0.6 \mathrm{~m}$ and the median energy period is $5.1 \mathrm{~s}$. This is expected since the average energy flux of the site, $3.4 \mathrm{~kW} / \mathrm{m}$, is small compared to the Swedish West coast in general and very small compared to the oceanic coast lines, e.g. Norway which in many places along its coastline has an average energy flux of at least a magnitude higher (Claeson 1987). Figure 7 also shows that most of the energy appearing over the studied period, year 2007, is contained in significant wave heights in the interval of 1.2-2.7 m, and energy periods in the interval of 5-7 s. Hence, these intervals represent the sea states that are the most interesting in the design of a wave energy converter that will be located at this site.

A conclusion from the results of the sea state measurements, in relation to the design of the WEC prototype, is that the stroke length of the generator might be slightly too short. As said, most of the energy is transmitted through wave heights of 1.2-2.7 m and the free stroke length is only $1.8 \mathrm{~m}$. The peak forces shown in Fig. 8 also indicate slightly too short stroke length. On the other hand, the associated costs of building a machine, which has a larger stroke length, has to be included and it might not be wise from an economic (cost of electricity production) point of view to make this alteration. Moreover, an increased machine length increases the bending moment at the lower end of the generator casing, where the machine is fastened to the concrete foundation. It increases the stress in the tubular casing and thus also increases the risk of local buckling in the casing and fatigue failure in various parts of the mechanical structure.

The force- and buoy acceleration data in Fig. 8 give very detailed information on the operation of the WEC. The measurements can, in general, be used to study maximum line forces, which also cause maximum material stress in parts of the structure. They can also be used to get information on mean stress levels for fatigue calculations and hence be used for material optimization. With these force measurements, it is also possible to verify the motion pattern of the translator, which otherwise is calculated from voltage output. If the sampling rate of the voltage measurements is insufficient, the calculation of translator speed and position will be quite inaccurate. High sampling rate of output voltage results in very large amounts of data to be stored. With one measurement channel for line force, which also has much lower sampling rate than the voltage measurements, a lot of useful information can be attained that is much harder or can not be attained from the voltage measurements.

The studied concept does not in principal allow a single generator to be operated, especially not connected to the grid. This is mainly due to the large short term variation in output power and the relatively small size of the WEC, which would make the costs of the electrical system too high for a single unit to bear. By adding capacitors with high capacitance after the diode rectifier, converting the generated AC to DC, a stable voltage and power production from one direct-driven linear generator can be achieved. However, the aim of this experiment was to demonstrate how the WEC will perform when it is interconnected with other WEC:s and not necessarily to demonstrate the operation of a 
single unit as a complete system. When more than one generator is connected in parallel to the system, the demand on the ability of the capacitive filter to store energy will decrease and hence also the costs associated with it. To compensate for voltage variations on the output that occur due to sea state variations, a DC/DC converter or a tap-changed transformer can be used.

By comparing Fig. 8 to Fig. 10, a difference in the shape of the voltage pulses is visible. In the former, the pulses are somewhat rounder. This is due to that the linear generator is directly connected to a resistive load, i.e. to a linear load. Power is extracted regardless of the level of generator voltage amplitude. This loading scheme (scheme for power extraction) also results in that the current will have more or less the same shape as the voltage. However, in Fig. 10, it is illustrated how the DC-voltage level limits the amplitude of the generator phase voltage. As soon as the phase voltage amplitude reaches the DCvoltage level, power will start flowing from the generator to the DC-side of the rectifier. Power will be delivered as long as the waves can deliver mechanical power to the buoy of the WEC, and as long as the translator of the WEC linear generator has not reached its upper or lower end stop. The current will increase as the speed of the translator increases. This non-linear power extraction scheme results in different shapes of the voltage and current pulses. In this non-linear case, the generator phase voltage will reach maximum amplitude, which is approximately equal to the DC-voltage.

In comparing the linear load-case with the non-linear load case, it can be seen that the speed of the translator is more constant during power extraction in the non-linear load case. The electrical frequency of the generator voltage is directly proportional to the speed of the translator. By studying the frequency of the voltage, is can thus be seen that the limitation of the generator voltage, which is achieved by controlling the DC-voltage level, also limits the translator speed to some extent and makes it more constant. If the translator speed is low, inducing a no-load voltage that is below the DC-voltage level, no power is extracted and so the speed of the translator is allowed to increase. The comparison between Figs. 8 and 10 hence represents a clear and concise illustration of the nature of the direct drive dynamics in this case.

In the Lysekil research area, the environmental impact has been studied. It focuses on mainly on marine organisms living in the seabed (the infauna), organisms involved in biofouling and on vertebrates (including fish, seabirds and marine mammals). For comparison, sampling has been done in the test area and in a reference area.

The sediments are characterized as transport bottoms where relatively rapid changes can occur. Prior to environmental permits being approved for the Lysekil research site, heavy trawling occurred in the area. This has affected the sediments with their infauna. Rapid changes in soft sediments favour small opportunistic species that colonise quickly after disturbances. Sediment samples have so far shown that only young and small organisms are found in the area. These species, which were found in the buoy area prior to launching of the wave energy converter and the biology buoys, are therefore most likely to be found in the same quantities after launching. Long-term studies of sediments in the research area after the launching of prototypes are important and on-going. We suggest that organisms in the area now have the possibility to recover after the heavy trawling that ended in 2003 , despite the research activities at the site.

Larger biodiversity in the test area compared to the control area can be explained by the variety of sediment substrate. Sediments in the test area contains both silt, sand and shell gravel whereas the control area contains silt and shell gravel. Silt is mostly relatively oxygen deficient and thus only a few organisms are adapted to these extreme conditions. The biodiversity in sandy sediments with medium grain size is most often higher than in 
other soft bottom types (Van Hoey et al. 2004). Soil conditions do matter for the diversity and biomass of infauna. Thus, for wave power devices anchored on soft sediments, it should be an important issue, which type of sediment and infauna the area contains.

Acknowledgments We thank the Swedish Energy Agency (STEM), Vattenfall AB, the Gothenburg Energy Research Foundation, Draka Cable AB, the Göran Gustavsson Research Foundation, Vargöns Research Foundation, Falkenberg Energy $\mathrm{AB}$ and Wallenius Foundation for supporting the experiments at the Lysekil research site. Ulf Ring is thanked for the practical work done and Mikael Eriksson and Karin Thorburn for their initial work within the project.

Open Access This article is distributed under the terms of the Creative Commons Attribution Noncommercial License which permits any noncommercial use, distribution, and reproduction in any medium, provided the original author(s) and source are credited.

\section{References}

Boström C, Lejerskog E, Tyrberg S et al (2008) Experimental results from an offshore wave energy converter. Presented in 27th international conference on offshore mechanics and Artic engineering, OMAE2008-57415

Callaway E (2007) To catch a wave. Nature 450(8):156-159. doi:10.1038/450156a

Cato I, Kjellin B (2008) Marine geological studys at the wave power plant outside Islandsberg, Bohuslän. Sveriges geologiska undersökning. SGU-rapport Uppsala, 10

Chabanet P, Ralambondrainy H, Amanieu M et al (1997) Relationships between coral reef substrata and fish. Coral Reefs 16:93-102. doi:10.1007/s003380050063

Claeson L (1987) Energi från havets vågor. Energiforskningsnämnden rapport nr 21. ISBN-91-38-09691-9. ISSN 0281-0301

Clark KR, Gorley RN (2006) PRIMER v6: User Manual/Tutorial. Primer-E Ltd, Plymouth, UK

Eriksson M, Isberg J, Leijon M (2005) Hydrodynamic modeling of a direct drive wave energy converter. Int J Eng Sci 43:1377-1387. doi:10.1016/j.ijengsci.2005.05.014

Eriksson M, Isberg J, Leijon M (2006) Theory and experiment of an elastically moored cylindrical buoy. IEEE Ocean Eng 31:959-963. doi:10.1109/JOE.2006.880387

Falnes J, Løvseth J (1991) Ocean wave energy. Energy Policy (October):768-775. doi:10.1016/03014215(91)90046-Q

Frigaard P, Kofoed JP, Knapp W (2004) Wave dragon. Wave power plant using low-head turbines. Hidroenergia 27-05

Gustafsson S, Svensson O, Sundberg J et al (2005) Experiments at Islandsberg on the west coast of Sweden in preparation of the construction of a pilot wave power plant. In: Proceedigns of the 6th EWTEC conference, Glasgow, UK, 197-201

Henderson R (2006) Design, simulations, and testing of a novel hydraulic power take-off system for the Pelamis wave energy converter. Renew Energy 31:271-283. doi:10.1016/j.renene.2005.08.021

Henfridsson U, Neimane V, Strand K et al (2007) Wave energy potential in the Baltic Sea and the Danish part of the North Sea, with reflections on the Skagerrak. Renew Energy 32:2069-2084. doi:10.1016/ j.renene.2006.10.006

Jensen AC (2002) Artificial reefs of Europe: perspective and future. ICES J Mar Sci 59:3-15. doi:10.1006/ jmsc. 2002.1298

Krebs CJ (1989) Ecological methodology. University of British Colombia, Harper and Row, Publishers, Inc, New York

Leijon M, Bernhoff H, Berg M et al (2003) Economical considerations of renewable electric energy production-especially development of wave energy. Renew Energy 28:1201-1209. doi:10.1016/ S0960-1481(02)00157-X

Leijon M, Bernhoff H, Ågren O et al (2005) Multiphysics simulation of wave energy to electric energy conversion by permanent magnet linear generator. IEEE Trans Energ Convers 20(1):219-224. doi: 10.1109/TEC.2004.827709

Luckhurst BE, Luckhurst K (1978) Analysis of the influence of substrate variables on coral reef communities. Mar Biol (Berl) 49:317-323. doi:10.1007/BF00455026

Marsh G (2007) Mixed mood at WATTS 2007, Offshore wind and marine project update, Renew Energy Focus, November/December 28-30 
Mueller MA, Baker NJ (2002) A low speed reciprocating permanent magnet generator for direct drive wave energy converters. Power electronics, machines and drives, 16-18 April 2002. IEE Conf Publ 487:468-473

Norris JV, Droniou E (2007) Update on EMEC activities, resource description, and characterization of wave-induced velocities in a tidal flow, In: Proceedings of the 7th EWTEC, 11-13 September, Porto, Portugal

Ocean Power Delivery (2004) Press release: First electricity from offshore wave power generated and supplied to the UK grid. Website, Available from http://oceanpd.com, [Last accessed June 2006]

Polinder H, Mecrow BC, Jack AG et al (2005) Conventional and TFPM linear generators for direct-drive wave energy conversion. IEEE Trans Energ Convers 20(2):260-267. doi:10.1109/TEC.2005.845522

Prado MGS, Neumann F, Damen ME C et al (2005) AWS results of pilot plant testing 2004. In: Proceedings of the 6th EWTEC, Glasgow, UK, 401-407

Risk MJ (1972) Fish diversity on a coral reef in the Virgin Islands. Atoll Res Bull 153:1-6

Soerensen HC, Friis-Madsen E, Panhauser W et al (2003) Development of Wave Dragon from Scale 1:50 to Prototype. In: Proceedings of the 5th EWTEC, Cork, Ireland

Stålberg M, Waters R, Danielsson O et al (2008) Influence of generator damping on peak power and variance of power for a direct drive wave energy converter. J Ocean Mech Arct Eng 130(3)

Sundberg, Langhamer (2005) Environmental questions related to point-absorbing linear wave generators: impact, effects and fouling. In: Proceedings of the 6th EWTEC, Glasgow, UK, 493-499

Thorburn K, Bernhoff H, Leijon M (2004) Wave energy transmission system concepts for linear generator arrays. Ocean Eng 31(11-12):1339-1349. doi:10.1016/j.oceaneng.2004.03.003

Van Hoey G, Degrear S, Vincx M (2004) Macrobenthic community structure of soft bottom sediments at the Belgian Continental Shelf. Estuar Coast Shelf Sci 59:599-613. doi:10.1016/j.ecss.2003.11.005

WaveNet (2003) Results from the work of the European Thematic Network on Wave Energy. European Community, ERK5-CT-1999-20001

Waters R, Stålberg M, Danielsson O et al (2007) Experimental results from sea trials of an offshore wave energy system. Appl Phys Lett, 90:034105 